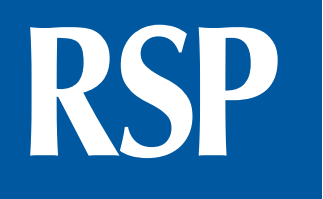

http://www.rsp.fsp.usp.br/

Revista de Saúde Pública

\title{
Happy life expectancy among older adults: differences by sex and functional limitations
}

\author{
Margareth G Lima', Ana Paula Belon", Marilisa BA Barros' \\ I Departamento de Saúde Coletiva. Faculdade de Ciências Médicas. Universidade Estadual de Campinas. \\ Campinas, SP, Brasil \\ " School of Public Health. University of Alberta. Alberta, Canada
}

\section{ABSTRACT}

OBJECTIVE: To evaluate if the happy life expectancy in older adults differs according to sex and functional limitations.

METHODS: Life expectancy was estimated by Chiang method, and happy life expectancy was estimated by Sullivan method, combining mortality data with the prevalence of happiness. The questions on happiness and limitations came from a health survey, which interviewed 1,514 non-institutionalized older adults living in the city of Campinas, SP, Southeastern Brazil. The happy life expectancy was estimated by sex, age, and functional limitations. Based on the variance and standard error of the happy life expectancy, we estimated $95 \%$ confidence intervals, which allowed us to compare the statistical differences of the number of happy years lived among men and women.

RESULTS: Differences by sex in happy life expectancy were significant at ages 60, 65, and 70 . In absolute terms, women live more years happily. But, in relative terms, older men could expect to live proportionally more years with happiness. Happy life expectancy decreased significantly with increasing age in both men and women. Among older people living without functional limitation, differences by sex were statistically significant in all age groups, except at age 80 . In the group with limitations, no significant differences by sex were found. Significant differences between the group without and with functional limitations were seen in both men and women.

Correspondence:

Departamento de Saúde Coletiva Rua Tessália Vieira de Camargo, 126 Cidade Universitária Zeferino Vaz 13083-887 Campinas, SP, Brasil E-mail: margarethglima@gmail.com

Received: 1 Oct 2015

Approved: 24 Jul 2016

How to cite: Lima MG, Belon AP, Barros MBA. Happy life expectancy among older adults: differences by sex and functional limitations. Rev Saude Publica. 2016;50:64.

Copyright: This is an open-access article distributed under the terms of the Creative Commons Attribution License, which permits unrestricted use, distribution, and reproduction in any medium, provided that the original author and source are credited.
CONCLUSIONS: Older men could expect to live a greater proportion of their lives happily in comparison to same-aged women, but women show more years with happiness than men. Functional limitations have a significant impact on happy life expectancy for both sexes.

DESCRIPTORS: Older adults. Happiness. Life Expectancy. Functional Disability. Quality of Life. Gender and Health. 


\section{INTRODUCTION}

Life expectancy (LE) has improved substantially since the past century, thanks to better living and health conditions ${ }^{8}$. In less than 25 years, the global life expectancy at birth increased from 64 to 71 years between 1990 and $2013^{23}$. Projections show that life expectancy will continue to increase, even in developed countries with the largest human lifespan ${ }^{8}$. In the last decades, an important question raised in public health is whether the increase of life expectancy would lead to possible health deterioration and worsening of well-being. To answer this question, researchers have investigated the healthy life expectancy, a measure that combines life expectancy with health indicators, such as morbidities (e.g., diabetes), self-rated health, functional capacity, quality of life and well-being ${ }^{19,24}$.

Under this investigation of the expansion of life years, an important issue is the morbidity-mortality paradox according to sex. It is well-known that women have more chronic diseases and functional limitations and complain more about health than men; however, they live longer than $\operatorname{men}^{15,17}$. The explanation to this paradox may be due to biological, sociocultural, and behavioral differences between men and women ${ }^{15}$. Given that the magnitude of health differences between men and women may vary according to the health indicator studied, some researchers have advocated for the use of different indicators, including the healthy life expectancy, to better understand the differences by sex in health ${ }^{17,19,24}$.

A step further taken by healthy life expectancy studies is the incorporation of the feeling of happiness, which is a well-being indicator used in several contexts of health research ${ }^{2,9}$. Resulted from the combination of the prevalence of happiness and mortality data, the happy life expectancy (happy LE) estimates how long people live and for how many years they live happily. Happy LE has some important particularities. First, the self-report of happiness is more subjective than the self-report of functional limitations and morbidities ${ }^{2,24}$. Second, it is more easily understood than quality of life (which is comprised of various meanings) ${ }^{21}$, summarizing the well-being in a more direct way.

Despite its advantages, a relative small number of studies have investigated happy LE by sex $^{19,24, a}$. Their findings have pointed out a greater absolute number of happy years among women ${ }^{24, a}$, but higher proportion of happy life years lived among men ${ }^{23}$.

According to some studies, aging does not lead to a reduction of the feeling of happiness and of proportion of happy years ${ }^{10,14,24}$; however, it leads to losses in different health domains, such as the increase in comorbidities and reduction of both physical and cognitive capacity ${ }^{7}$. The functional capacity is defined as the ability to perform daily activities, including for mobility (e.g., climbing a flight of stairs) and self-care (e.g., using the toilet) ${ }^{16}$. It is a key health domain for ensuring the autonomy and independence of older adults, and preserving their quality of life $\mathrm{e}^{22}$.

To our best knowledge, no Brazilian studies have examined happy LE among the Brazilian older population and have stratified it according to the presence of functional limitations. Therefore, because of the lack of knowledge on this subject up to now, this study aimed to evaluate the differences by sex in happy LE among Brazilian older adults, as well as analyze happy LE by the presence of functional limitations.

a Kunst AE, Okma-Keulen PT, Veenhoven R. Happy life expectancy in 5 European countries. XIII World Congress of Sociology Bielefeld, Germany 1994 [cited 2016 Sept 13]. Available from: https://personal.eur.nl/ veenhoven/Pub1990s/94f-full.pdf
Our hypothesis is that both older men and women with no functional limitation would present higher happy LE than their respective counterparts living with one or more functional limitations, given the strong association of functional capacity on well-being ${ }^{9,14}$. A secondary hypothesis is that women would have higher happy LE in absolute terms, considering that (1) they live longer and (2) the feeling of happiness does not necessarily decrease with the increase of age. 


\section{METHODS}

Our study uses data from the 2008 ISACamp, which is a population-based household survey on health conditions conducted in Campinas, SP, Brazil, in the year of 2008. To estimate a prevalence of $50.0 \%$ with $95 \%$ confidence intervals, a sampling error of $4.0 \%-5.0 \%$, and a design effect of two, the minimum sample size was estimated in 1,000 older adults.

This survey used a two-stage sample design. First, we selected 50 census tracts with a probability proportional to the number of households in each unit. Then, households were randomly sampled in each census tract selected. Using the 2010 census population distribution, we estimated the probability of older adults living in the households; this probability determined the number of households to be visited. The sample size was comprised of 3,900 households, already considering a possible loss of $20.0 \%$ due to refusals and closed households. In total, 1,519 older adults were interviewed.

To develop abridged life tables by sex, we used mortality data from Sistema de Informações sobre Mortalidade (SIM - Mortality Information System) ${ }^{\mathrm{b}}$ and 2008 population data from Fundação Sistema Estadual de Análise de Dados (SEADE - Sao Paulo State Data Analysis System Foundation) ${ }^{\mathrm{c}}$.

Participants were asked to evaluate their happiness by responding a single question: "How much of the time have you felt happy during the past four weeks?" Participants were asked to give the one answer that would come closest to the way they were feeling. We dichotomized the responses to code happiness: the answers "all the time" and "most of the time" were scored as "zero" (happy status), while "some of the time", "a little of the time", and "none of the time" were scored as "one" (unhappy status).

In addition to happiness, we used a measure of functional limitations. Participants were asked if they had any limitation when performing the following activities: walking more than one mile, walking several blocks, walking one block, and eating or bathing themselves. Their answers were dichotomized: without any functional limitation and with at least one functional limitation. Similar questions were used in other studies ${ }^{3,5}$.

We estimated age-specific mortality rates for five-year intervals from 60 years to 80 years or older, using 2007-2009 triennium mortality data and 2008 population. The mortality rates were then converted into death probabilities at exact age, which were used to obtain the life expectancy. We used Chiang method ${ }^{6}$ to construct abridged life tables for men and for women.

Happy LE was estimated using Sullivan method ${ }^{18}$, which uses the prevalence of happiness in each age group to determine the average number of life years that would be lived with and without happiness. Sullivan method divides the number of person-years (a function of the life table) into years to be lived with and without a certain health condition for each specific age group. Happy LE was calculated for each age group, sex, and functional limitation group (with or without).

This study was approved by the University of Campinas Research Ethics Committee (Process: 841.196). Informed consent was obtained from all participants.

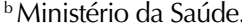

Sistema de Informações sobre Mortalidade - SIM . Available from: http://svs.aids.gov.br/cgiae/sim/ c Fundação Sistema Estadual de Análise de Dados - SEADE. Available from: http://www. seade.gov.br/

\section{RESULTS}

Table 1 presents the estimates of happiness prevalence rates for age groups and sex. There were no significant changes in the prevalence of happiness with age for both men and women. For each age group, no differences by sex were detected.

The estimates of life expectancy and happy LE for men and women are shown in Table 2. Differences by sex in life expectancy were significant in all age groups; they decreased with age, from 4.5 years at age 60 to 2.0 years at age 80. For happy LE (in years), the number of happy years lived decreased with age in both sexes. Differences by sex in 
Table 1. Prevalence of happiness by sex and age. Campinas, SP, Southeastern Brazil, 2008.

\begin{tabular}{|c|c|c|c|c|c|c|c|c|c|}
\hline \multirow{3}{*}{$\begin{array}{l}\text { Age } \\
\text { groups }\end{array}$} & \multicolumn{4}{|c|}{ Males } & \multicolumn{4}{|c|}{ Females } & \multirow[t]{2}{*}{$\begin{array}{l}\text { Differences } \\
\text { by sex }\end{array}$} \\
\hline & \multicolumn{8}{|c|}{ Happiness } & \\
\hline & $\mathbf{n}$ & $\%^{a}$ & $95 \% \mathrm{Cl}$ & $\mathbf{p}^{\mathbf{b}}$ & $\mathbf{n}$ & $\%^{a}$ & $95 \% \mathrm{Cl}$ & $\mathbf{p}^{\mathbf{b}}$ & $\mathbf{p}^{c}$ \\
\hline 60 & 218 & 82.0 & $74.6-87.6$ & 0.1618 & 256 & 75.7 & $68.4-81.7$ & 0.1379 & 0.0606 \\
\hline 65 & 132 & 83.9 & $75.8-89.7$ & & 214 & 77.9 & $70.5-83.8$ & & 0.2099 \\
\hline 70 & 116 & 75.1 & $66.1-82.4$ & & 164 & 68.9 & $58.6-77.6$ & & 0.3882 \\
\hline 75 & 81 & 72.0 & $63.8-78.9$ & & 136 & 72.5 & $62.5-80.7$ & & 0.9204 \\
\hline$\geq 80$ & 66 & 79.2 & $66.2-88.1$ & & 131 & 66.5 & $55.6-73.6$ & & 0.0793 \\
\hline
\end{tabular}

aeighted.

p-value related to age differences in each sex (at the $5 \%$ level).

${ }^{c} p$-value related to the differences between sexes in each age group (at the $5 \%$ level).

Table 2. Life expectancy and happy life expectancy by sex and age. Campinas, SP, Southeastern Brazil, 2008

\begin{tabular}{|c|c|c|c|c|c|c|c|c|c|c|}
\hline \multirow{4}{*}{ Age } & \multicolumn{5}{|c|}{ Life expectancy } & \multicolumn{5}{|c|}{ Happy life expectancy } \\
\hline & \multicolumn{2}{|c|}{ Males } & \multicolumn{2}{|c|}{ Females } & \multirow{3}{*}{$\begin{array}{c}\text { Differences } \\
\text { by sex } \\
(B-A)^{a}\end{array}$} & \multicolumn{2}{|c|}{ Males } & \multicolumn{2}{|c|}{ Females } & \multirow{3}{*}{$\begin{array}{c}\begin{array}{c}\text { Differences } \\
\text { by sex }\end{array} \\
(D-C)^{a}\end{array}$} \\
\hline & Years & $95 \% \mathrm{Cl}$ & Years & $95 \% \mathrm{Cl}$ & & Years & $95 \% \mathrm{Cl}$ & Years & $95 \% \mathrm{Cl}$ & \\
\hline & & (A) & & (B) & & & (C) & & (D) & \\
\hline 60 & 19.2 & $18.2-20.2$ & 23.7 & $22.8-24.6$ & $4.5^{\mathrm{b}}$ & 15.2 & $14.5-15.8$ & 17.1 & $16.3-17.8$ & $1.9^{\mathrm{b}}$ \\
\hline 65 & 15.6 & $14.6-16.5$ & 19.6 & 18.8-20.5 & $4.0^{\mathrm{b}}$ & 12.2 & $11.5-12.8$ & 13.9 & $13.2-14.6$ & $1.7^{\mathrm{b}}$ \\
\hline 70 & 12.4 & $11.5-13.2$ & 15.7 & $15.0-16.5$ & $3.4^{\mathrm{b}}$ & 9.4 & $8.7-10.0$ & 10.8 & $10.1-11.5$ & $1.4^{\mathrm{b}}$ \\
\hline 75 & 9.4 & $8.7-10.2$ & 12.3 & $11.7-12.9$ & $2.9^{\mathrm{b}}$ & 7.2 & $6.5-7.8$ & 8.4 & $7.7-9.2$ & 1.2 \\
\hline $80^{c}$ & 7.3 & & 9.3 & & 2.0 & 5.8 & $5.0-6.5$ & 6.2 & $5.4-6.9$ & 0.4 \\
\hline
\end{tabular}

at the $5.0 \%$ level.

Statistically significant differences by sex.

c Note: $95 \%$ confidence intervals for life expectancy could not be estimated for the age 80 .

happy LE were significant at ages 60,65 , and 70, with women living more years happily. Men aged 60 could expect to live 15.2 years happily, while women at same age would live 17.1 years - a significant difference of 1.9 years. But, in relative terms, older men could expect to live proportionally more years with happiness in comparison to older women; this difference increased with age and was larger at age 80 (Figure 1). While the proportion of happy years showed almost no change with age among men, it decreased among women.

Regarding happy LE according to functional limitations (Table 3), the happy years gradually decrease with increasing age in men and women for older adults with and without functional limitations. Among older adults living without functional limitation, differences by sex were statistically significant in all age groups, except at age 80 . In the group with at least one functional limitation, no significant differences by sex were found.

Analyzing men and women separately, one can observe significant differences between the group without and with functional limitations. Except for those aged 75 years, men without any functional limitations could expect to live significantly more years than men with at least one functional limitation. The same pattern can be seen for women at ages 60 and 65 . At age 60, men and women without functional limitations would live 3.3 years more than their counterparts living with at least one functional limitation. The difference reduced with the increase of age in both men and women. 
Table 3. Happy life expectancy by sex, according to functional disability. Campinas, SP, Southeastern Brazil, 2008.

\begin{tabular}{|c|c|c|c|c|c|c|c|c|c|c|c|c|}
\hline \multirow{3}{*}{ Age } & \multicolumn{5}{|c|}{ Without limitations } & \multicolumn{5}{|c|}{ With limitations } & \multicolumn{2}{|c|}{$\begin{array}{l}\text { Without - with } \\
\text { limitations }\end{array}$} \\
\hline & \multicolumn{2}{|c|}{ Males } & \multicolumn{2}{|c|}{ Females } & \multirow{2}{*}{$\begin{array}{c}\begin{array}{c}\text { Diferences } \\
\text { by sex }\end{array} \\
(B-A)^{a}\end{array}$} & \multicolumn{2}{|c|}{ Males } & \multicolumn{2}{|c|}{ Females } & \multirow{2}{*}{$\begin{array}{c}\begin{array}{c}\text { Diferences } \\
\text { by sex }\end{array} \\
(D-C)^{a}\end{array}$} & \multirow{2}{*}{$\frac{\text { Males }}{(\mathrm{A}-\mathrm{C})^{\mathrm{a}}}$} & \multirow{2}{*}{$\begin{array}{r}\text { Females }^{(\mathrm{B}-\mathrm{D})^{\mathrm{a}}} \\
\end{array}$} \\
\hline & $\begin{array}{l}\text { Years } \\
\text { (A) }\end{array}$ & $95 \% \mathrm{Cl}$ & $\begin{array}{l}\text { Years } \\
\text { (B) }\end{array}$ & $95 \% \mathrm{Cl}$ & & $\begin{array}{l}\text { Years } \\
\text { (C) }\end{array}$ & $95 \% \mathrm{Cl}$ & $\begin{array}{l}\text { Years } \\
\text { (D) }\end{array}$ & $95 \% \mathrm{Cl}$ & & & \\
\hline 60 & 16.5 & $15.8-17.2$ & 19.0 & $17.9-20.0$ & $2.5^{\mathrm{b}}$ & 13.2 & $12.0-14.4$ & 15.7 & $13.8-17.5$ & 2.5 & $3.3^{\mathrm{b}}$ & $3.3^{\mathrm{b}}$ \\
\hline 65 & 13.5 & $12.8-14.2$ & 15.8 & $14.7-16.8$ & $2.3^{\mathrm{b}}$ & 10.4 & $9.3-11.6$ & 12.8 & $11.1-14.5$ & 2.4 & $3.1^{\mathrm{b}}$ & $3.0^{\mathrm{b}}$ \\
\hline 70 & 10.5 & $9.7-11.2$ & 12.5 & $11.5-13.6$ & $2.0^{\mathrm{b}}$ & 8.2 & $7.2-9.2$ & 10.1 & $8.6-11.6$ & 1.9 & $2.3^{\mathrm{b}}$ & 2.4 \\
\hline 75 & 8.1 & $7.3-8.8$ & 10.2 & $9.1-11.3$ & $2.1^{\mathrm{b}}$ & 6.4 & $5.4-7.4$ & 7.7 & $6.3-9.2$ & 1.3 & 1.7 & 2.5 \\
\hline$\geq 80$ & 6.8 & $6.1-7.4$ & 7.9 & $6.7-9.0$ & 1.1 & 4.9 & $3.8-6.0$ & 5.6 & $4.2-7.0$ & 0.7 & $1.8^{\mathrm{b}}$ & 2.3 \\
\hline
\end{tabular}

${ }^{a}$ At the $5 \%$ level.

b Statistically significant differences by sex.

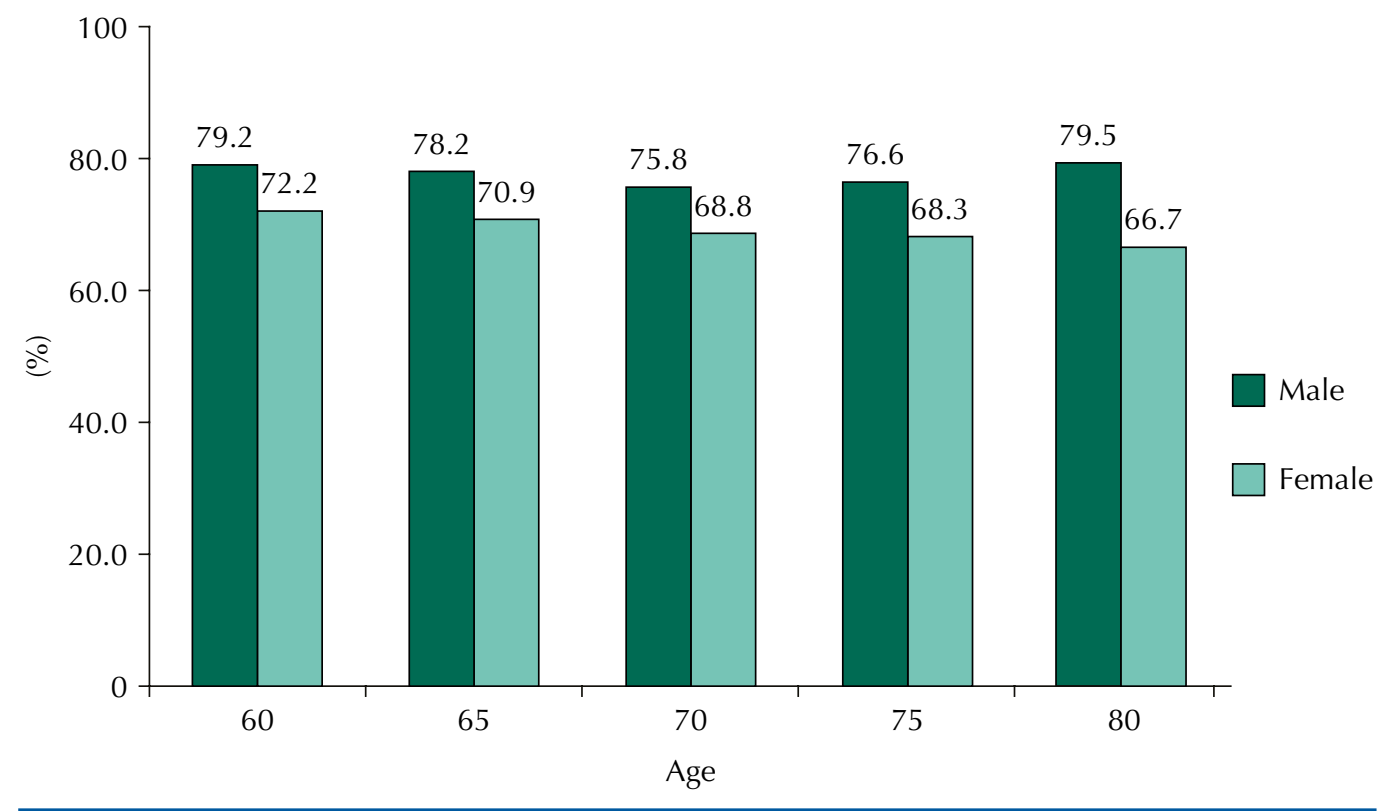

Figure 1. Proportion of happy life expectancy by sex and age.

The proportion of years lived happily reduced considerably in the group with functional limitations in comparison to the group without functional limitations, for men and for women (Figure 2).

\section{DISCUSSION}

Our study examined how long Brazilian older adults aged 60 years or more can expect to live happily. The estimates were disaggregated by five-year age groups and sex. The analysis was also stratified by the absence and presence of functional limitations. Happy LE resulted from the combination of life expectancy and feeling of happiness measured in the past four weeks before the survey.

With the expansion of the longevity, the research on quality of life years gained and sex inequalities on health and mortality has made important progress thanks to estimation of healthy life expectancy ${ }^{17}$. Studies have calculated healthy life expectancy in combination with specific diseases, functional limitations ${ }^{1,5}$, and self-rated health ${ }^{3}$, which can be interpreted as indirect measures of well-being and quality of life $4^{4}$. However, studies on 


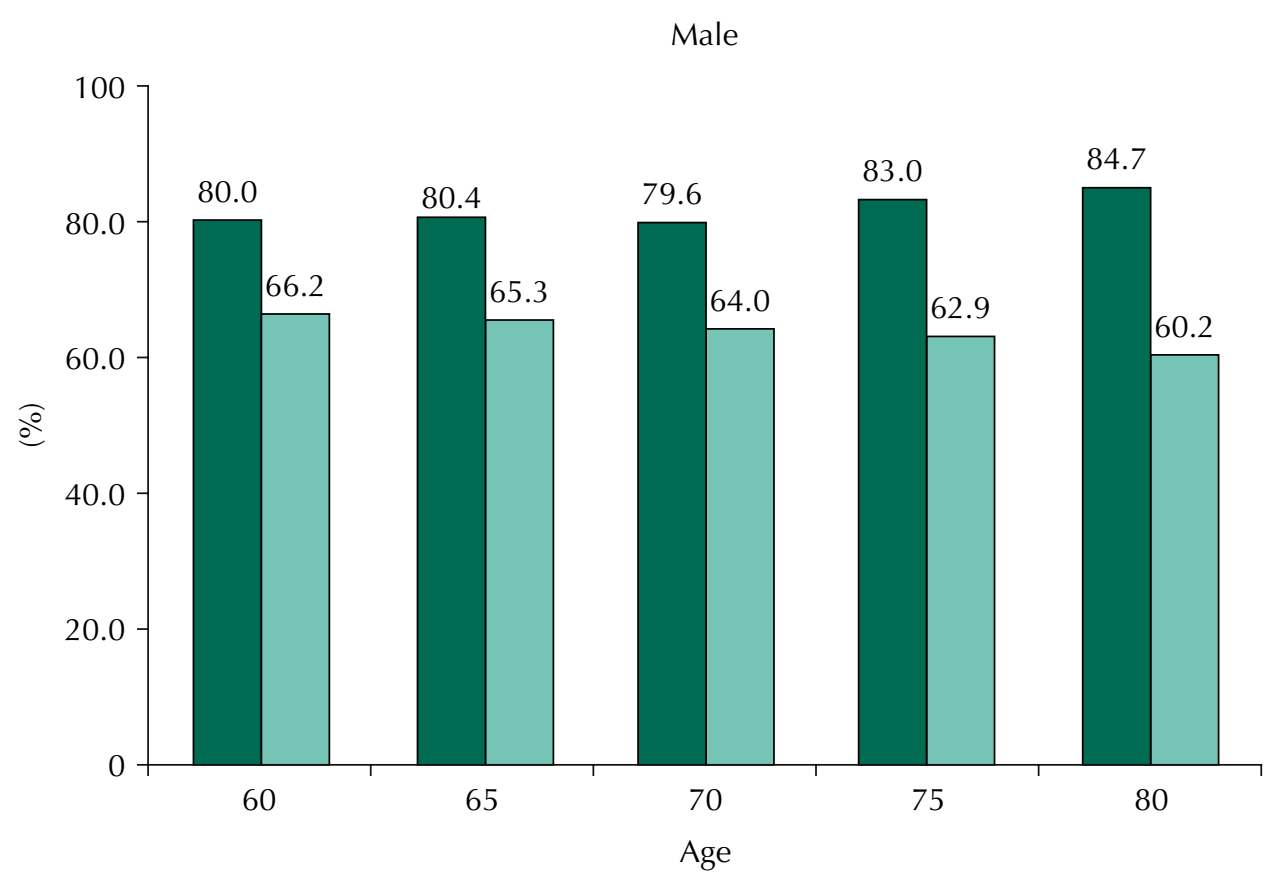

Female

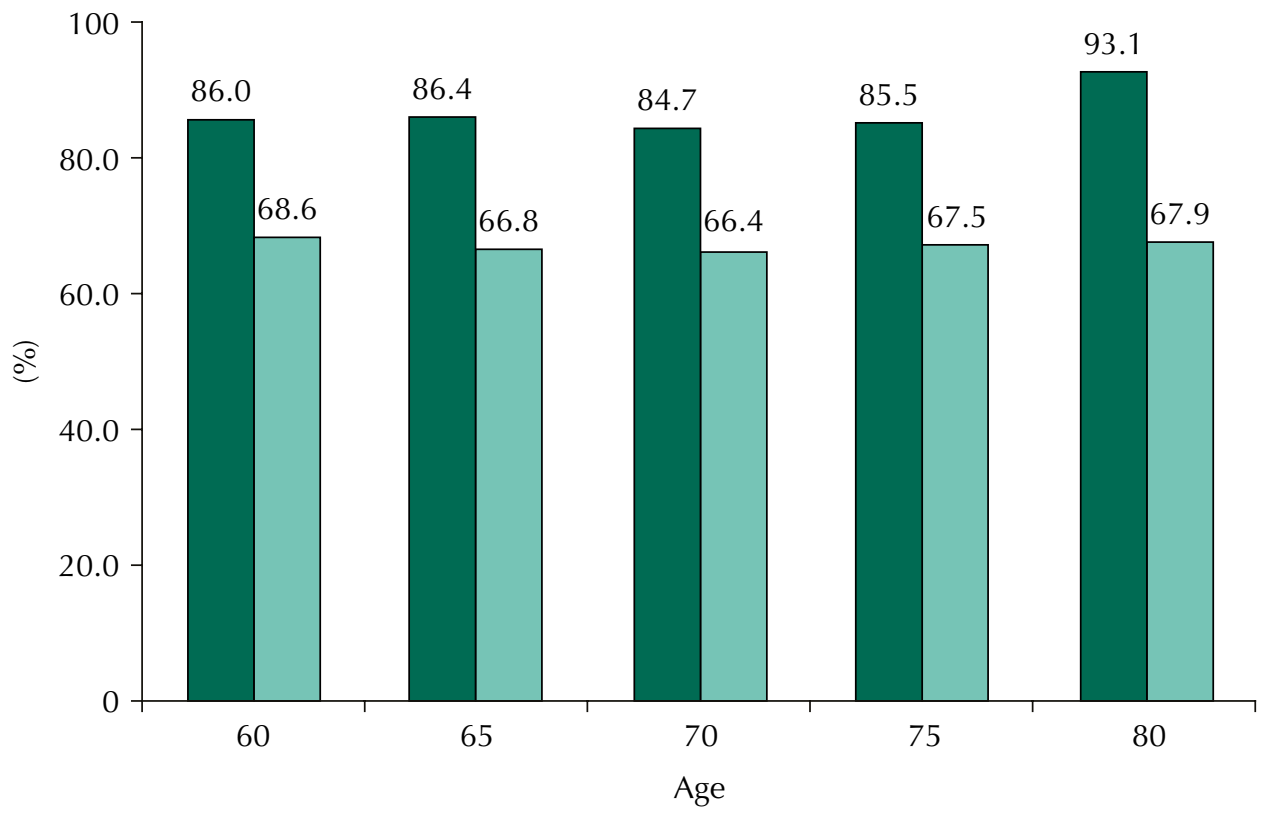

Without limitations $\quad \square$ With limitations

Figure 2. Proportion of happy life expectancy according to functional disability, by sex and age.

happy LE are still emerging in the literature. Most studies ${ }^{15,20,24}$ have compared the number of happy years among countries and have used data from the World Database of Happiness project, which has compiled surveys on happiness worldwide since the post-war period ${ }^{20}$. Little work has been done to estimate happy LE in Latin America, and more specifically in Brazil. Our study may be the first one analyzing differences by sex in happy LE among Brazilian older adults.

Consistent with other studies ${ }^{10,14}$, no differences by sex in the prevalence rate of happiness were found; however, they did exist in the happy LE. At ages 60, 65, and 70, the number of happy years expected to be lived were significantly higher among women, while the proportion of happy years is greater among men. These findings confirm a previous research showing that women from the five countries studied would live more years in total and happily than men ${ }^{\mathrm{a}}$. A study analyzing the United States trends and patterns of happy LE 
between 1970 and 2000 found similar results: in comparison to men, happy LE estimated for women was greater in absolute terms, but smaller in relative terms ${ }^{24}$. However, while this study showed no change with age in the proportions of happy LE among older men and women, we found that the proportion of happy life years decreases with age in the female population, but it does not change in the male population.

Using data from 45 countries, a study compared differences by sex in healthy life expectancy with several morbidity and functional limitation indicators. The results showed a female advantage in terms of life expectancy (on average, 6.3 years higher than male life expectancy) and healthy life expectancy, in absolute and relative terms ${ }^{15}$. Based on these findings, the authors suggested that women have a higher healthy life expectancy because they have a longer life expectancy. However, findings from different studies on differences by sex in healthy life expectancy are divergent, when indicators of functional limitations and self-rated health were used. Some studies have shown that women could expect to live higher proportion of their lives in good health ${ }^{3}$, while others found the opposite ${ }^{1,13}$.

Previous studies have also detected that the female or male advantage in the healthy life expectancy depends on the health indicator used ${ }^{3}$ and level of mortality of the countries ${ }^{19}$. Belon et al. ${ }^{3}$ found different results according to the health indicator studied: older Brazilian women could expect to live longer and most of the years would be spent with better self-rated health. However, they would live more years with functional limitations in contrast to older Brazilian men. Using data on disability prevalence from 25 European countries, a study on healthy life expectancy showed that in populations with high life expectancy women could expect to live more unhealthy years than men; in contrast, in countries with low life expectancy men could expect to live a shorter life expectancy and longer unhealthy life expectancy with poorer health ${ }^{19}$.

Our study also estimated the happy LE according to the presence of functional limitations. Our research, performed with the same population of this study, showed that functional limitation is significantly higher among women than men who are aged 80 years or older, and functional limitation tends to increase with age in both sexes ${ }^{3}$.

To our best knowledge, this is the first study that analyzed these conditions in combination with happiness. In comparison to the absence of functional limitations, the male and female happy LE reduced significantly in both absolute and relative terms. Other studies showed a strong association between functional limitations and happiness9,14. In our previous study, with the same Brazilian sample, we found an association between happiness and functional limitations; the prevalence of happiness was 2.5 times higher among older adults without than with functional limitations ${ }^{14}$. Examining the relationship of life satisfaction and perception of future happiness with functional status, an eight-year cohort study with 3,363 people found that well-being is a protective factor from increased mobility limitations ${ }^{9}$.

Regarding the older adults who did not report the functional limitations studied, happy LE statistically differed between sexes, with a female advantage. However, among older adults who reported one or more functional limitations, these differences were not significant. These findings suggest that functional limitations may have a substantial negative impact on the happiness levels of older adults. Therefore, the promotion of an active aging with more years free of functional limitations coupled with compensatory strategies supporting autonomy and independence among older adults are fundamental for their quality of life and happiness ${ }^{22}$. According to Van Oyen et al. ${ }^{19}$, the higher prevalence of functional limitations among women is responsible for decreasing the differences by sex in healthy life expectancy, which otherwise would be greater.

The limitations of this study are related to the question about happiness used. Although this question is part of an instrument that assesses health-related quality of life (i.e., SF-36) and is not meant to be used separately, it is still a sensible, valid indicative of happiness. First, because the question considers the frequency and duration of happiness, which has been 
considered a better indicative of well-being in comparison to the intensity of happiness ${ }^{12}$. Second, because it is efficient to measure happiness at population level ${ }^{11}$. Another limitation of this study is that institutionalized Brazilian older adults were not included. Although less than $1.0 \%$ of the total older population lives in long-term care facilities ${ }^{\mathrm{d}}$, the generalizability of our findings may be limited.

On the other hand, this study has several strengths. First, it adds some evidence to the limited international literature on happy LE, especially on differences by sex in happy life years in the presence of functional limitations. Second, to our best knowledge, this is the first study analyzing differences by sex in happy LE using data from Brazilian surveys. Third, this study is among the first ones that estimate $95 \%$ confidence intervals of happy LE, which enables us to analyze the statistical significance when comparing results.

Our research found that older women would live longer than men and with more happy years. However, older men could expect to live a greater proportion of their lives happily in comparison to same-aged women. Happy LE decreased significantly with age among older men and women, including among those who reported no or at least one functional limitation. No difference by sex among older adults with functional limitations was detected. The proportion of happy LE did not increase with age among men and women with no functional limitations, although it was relatively larger at age 80 in both sexes. Among men and women who have at least one functional limitation, the proportion of happy LE decreased with age.

Given our findings, it is clear the relevance of strategies that help maintain older adults' autonomy and independence, which are essential to their well-being and feeling of happiness. More importantly, our study suggests that if men had a longer life expectancy than women, they could expect to live more years happily than women. Thereby, health research and public policies should consider the differences by sex, besides the quantity of years to be lived and quality of life.

\section{REFERENCES}

1. Andrade FCD, Guevara PE, Lebrão ML, Duarte YAO, Santos JLF. Gender differences in life expectancy and disability-free life expectancy among older adults in São Paulo Brazil. Womens' Health Issues. 2011;21(1):64-70. DOI:10.1016/j.whi.2010.08.007

2. Angner E, Saag KG, Allison JJ. Health and happiness among adults: a community-based study. J Health Psychol. 2009;14(4):503-12. DOI:10.1177/1359105309103570

3. Belon AP, Lima MG, Barros MBA. Gender differences in healthy life expectancy among Brazilian elderly. Health Qual Life Outcomes. 2014;12(1):88-98. DOI:10.1186/1477-7525-12-88

4. Broome J. Measuring the burden of disease by aggregating well-being. In: Murray CJL, Joshua AS, Mathers CD, Lopez A. Summary measures of population health: concepts, ethics, measurement and applications. Geneva: World Health Organization; 2002.

5. Camargos MCS, Machado CJ, Rodrigues RN. Life expectancy among elderly Brazilians in 2003 according to different levels of functional disability. Cad Saude Publica. 2008a;24(4):845-52. DOI:10.1590/S0102-311X2008000400015

6. Chiang CL. The life table and its applications. Malabar, FL: Robert E. Krieger Publishing Company; 1984.

7. Cho J, Martin P, Poon LW. The older they are the less successful they become? Findings from the Georgia Centenarian Study. J Aging Res. 2012;2012;ID695854. DOI:10.1155/2012/695854

8. Christensen K, Doblhammer G, Rau R, Vaupel JW. Ageing populations: the challenges ahead. Lancet. 2009;374(9696):1196-208. DOI:10.1016/S0140-6736(09)61460-4

${ }^{\mathrm{d}}$ Instituto de Pesquisa Econômica Aplicada (IPEA).Condições de funcionamento e infraestrutura das instituições de longa permanência para idosos no Brasil. Brasília (DF): IPEA; 2011 (Comunicado do IPEA, Vol 93).
9. Collins AL, Goldman N, Rodríguez G. Is positive well-being protective of mobility limitations among older adults? J Gerontol B Psychol Soc Sci. 2008;63(6):321-7. DOI:10.1093/geronb/63.6.P321

10. Cooper C, Bebbington P, King M, Jenkins R, Farrell M, Brugha T et al. Happiness across age groups: results from the 2007 National Psychiatric Morbidity Survey. Int J Geriatr Psychiatry. 2011;26(6):608-14. DOI:10.1002/gps.2570 
11. Diener E. Subjective well-being. Psychol Bull. 1984;95(3):542-75. DOI:10.1037/0033-2909.95.3.542

12. Diener E. Subjective well-being: the science of happiness and a proposal for a national index. Am Psychol. 2000;55(1):34-43. DOI:10.1037/0003-066X.55.1.34

13. Gu D, Dupre ME, Warner DF, Zeng Y. Changing health status and health expectancies among older adults in China: gender differences from 1992 to 2002. Soc Sci Med. 2009;68(12):2170-9. DOI:10.1016/j.socscimed.2009.03.031

14. Lima MG, Barros MBA, Alves MCGP. Sentimento de felicidade em idosos: uma abordagem epidemiológica, ISA-Camp 2008. Cad Saude Publica. 2012;28(12):2280-92. DOI:10.1590/S0102-311X2012001400007

15. Luy M, Minagawa Y. Gender gaps: life expectancy and proportion of life in poor health. Health Rep. 2014;25(12):12-9.

16. McDowell I. Measuring health: a guide to rating scales and questionnaires. 3rd ed. New York: Oxford University Press; 2006.

17. Oksuzyan A, Brønnum-Hansen H, Jeune B. Gender gap in health expectancy. Eur J Ageing. 2010;7(4):213-8. DOI:10.1007/s10433-010-0170-4

18. Sullivan DF. A single index of mortality and morbidity. HSMHA Health Rep. 1971;86(4):347-54. DOI:10.2307/4594169

19. Van Oyen H, Nusselder W, Jagger C, Kolip P, Cambois E, Robine J. Gender differences in healthy life years within the EU: an exploration of the "health-survival" paradox. Int J Public Health. 2013;58(1):143-55. DOI: 10.1007/s00038-012-0361-1

20. Veenhoven R, Ehrhardt J, Ho Dhian MS, de Vries A. Hapiness in nations: subjective appreciation of life in 56 nations 1946-1992. Studies in sociocultural transformation, No 2. Rotterdan, NL: Erasmus University; 1993. p. 365.

21. Veenhoven R. Apparent quality-of-life in nations. How long and happy people live. Soc Indic Res. 2005;71(1-3):61-8. DOI:10.1007/s11205-004-8014-2

22. World Health Organization (WHO). Active aging: a policy framework. Geneva: World Health Organization; 2002. (WHO/NMP/NPH/02.8).

23. World Health Organization (WHO). World Health Statistics 2015. Geneva: World Health Organization; 2015.

24. Yang Y. Long and happy living: trends and patterns of happy life expectancy in the U.S., 1970-2000. Soc Sci Res. 2008;37(4):1235-52. DOI:10.1016/j.ssresearch.2007.07.004

Funding: The health survey (ISACamp 2008) was funded by CNPq (Process 409747/2006-8) and had financial support of the Municipal Health Secretariat of Campinas (Partnership UNICAMP/Funcamp/SMS 4300).

Author's Contribution: Data analysis and interpretation: MGL, APB, MBAB. Drafting of the text: MGL, APB. Critical revision of the manuscript: MGL, APB, MBAB.

Conflict of Interest: The authors declare no conflict of interest. 